\title{
Uso de Tecnologias Digitais como Instrumentos nas Práticas de Preservação e Valorização do Patrimônio Urbano e Arquitetônico de Dracena - SP
}

Use of Digital Technologies as Instruments in the Practices of Preservation and Valorization of the Urban and Architectural Heritage of Dracena - SP

Uso de Tecnologías Digitales como Instrumentos en las Prácticas de Preservación y Valorización del Patrimonio Urbano y Arquitectónico de Dracena - SP

Maria Paula Hêngling Christófani Estudante de graduação, FCT UNESP, Brasil mariapaula.hec@gmail.com

Hélio Hirao Professor Doutor, FCT UNESP, Brasil helio.hirao@unesp.br 


\title{
Revista Científica ANAP Brasil
}

\author{
ISSN 1984-3240 - Volume 13, número 29, 2020
}

\section{RESUMO}

$\mathrm{Na}$ atual era da informatização, é cada vez mais constante a relação entre as tecnologias digitais e seus usuários. As frequentes inovações das tecnologias da informação e comunicação ampliam as possibilidades de aproximação e valorização do patrimônio histórico e cultural, uma vez que proporcionam à sociedade a troca de conteúdos, a respeito dos bens patrimoniais, com maior praticidade, rapidez e interação. Desta forma, o presente artigo traz experimentações de práticas de educação patrimonial a partir do emprego das ferramentas que as tecnologias digitais oferecem. Tem como objetivo a elaboração e teste de um modelo de identificação patrimonial, que contribua para potencializar os processos de valorização e preservação do patrimônio urbano e arquitetônico da cidade de Dracena - São Paulo, tendo em vista que a cidade ainda apresenta registros materiais do início de sua ocupação. Para isso realizou-se uma revisão do reconhecimento do patrimônio urbano e arquitetônico da cidade de Dracena - SP; seguido de um levantamento bibliográfico de formas de emprego das Tecnologias Digitais como instrumentos voltados à valorização do Patrimônio Urbano e Arquitetônico; por fim, devido ao subsídio proporcionado pelo estudo, foi elaborado e testado um modelo de identificação patrimonial. Durante o período de teste, uma quantidade razoável de pessoas utilizou o modelo e deixaram contribuições, este fato permitiu avaliar como positiva a contribuição proposta.

PALAVRAS-CHAVE: Tecnologias Digitais. Patrimônio. Educação Patrimonial.

\section{ABSTRACT}

In the current era of computerization, the relationship between digital technologies and their users is increasingly constant. Frequent innovations in information and communication technologies expand the possibilities of approaching and enhancing the historical and cultural heritage, since they provide society with an exchange of contents, regarding heritage assets, with greater practicality, speed and interaction. In this way, this article brings experiments with heritage education practices using the tools offered by digital technologies. Its objective is the elaboration and testing of a patrimonial identification model, which contributes to enhance the processes of valorization and preservation of the urban and architectural heritage of the city of Dracena - São Paulo, considering that the city still presents material records from the beginning of your occupation. For this, a revision of the recognition of the urban and architectural heritage of the city of Dracena - SP was carried out; followed by a bibliographic survey of forms of use of Digital Technologies as instruments aimed at enhancing the Urban and Architectural Heritage; finally, due to the subsidy provided by the study, an patrimonial identification model was developed and tested. During the test period, a reasonable number of people used the model and left contributions, this fact allowed to evaluate the proposed contribution as positive.

KEYWORDS: Digital Technologies. Patrimony. Patrimonial Education.

\section{RESUMEN}

En la era actual de la informatización, la relación entre las tecnologías digitales y sus usuarios es cada vez más constante. Las frecuentes innovaciones en las tecnologías de la información y la comunicación amplían las posibilidades de acercarse y mejorar el patrimonio histórico y cultural, ya que proporcionan a la sociedad un intercambio de contenidos sobre activos patrimoniales, con mayor practicidad, velocidad e interacción. De esta manera, este artículo trae experimentos con prácticas de educación patrimonial utilizando las herramientas que ofrecen las tecnologías digitales. Su objetivo es la elaboración y prueba de un modelo de identificación patrimonial, que contribuya a mejorar los procesos de valorización y preservación del patrimonio urbano y arquitectónico de la ciudad de Dracena - São Paulo, considerando que la ciudad aún presenta registros materiales del comienzo de su ocupación. Para eso, se realizó una revisión del reconocimiento del patrimonio urbano y arquitectónico de la ciudad de Dracena - SP; seguido de una búsqueda bibliográfica sobre las formas de uso de las tecnologías digitales como instrumentos destinados a valorización del patrimonio urbano y arquitectónico; finalmente, debido al subsidio provisto por el estudio, se desarrolló y probó un modelo de identificación patrimonial. Durante el período de prueba, un número razonable de personas utilizó el modelo y dejó contribuciones, este hecho permitió evaluar la contribución propuesta como positiva.

PALABRAS CLAVE: Tecnologías digitales. Patrimonio. Educación patrimonial. 


\section{Revista Científica ANAP Brasil}

ISSN 1984-3240 - Volume 13, número 29, 2020

\section{Introdução}

O processo de transformação constante da paisagem urbana das cidades, devido a descontextualização de suas ambiências, juntamente com os avanços tecnológicos, tem ocorrido de forma cada vez mais acelerada. Este processo promove modificações e remodelações de espaços públicos e privados, incidindo diretamente nos hábitos, vivências e relações das pessoas com o espaço. Como consequência deste processo, a perda do reconhecimento e do sentimento de pertencimento das comunidades com a cidade é observada, uma vez que este incide sobre a memória afetiva das pessoas e sobre os próprios elementos da paisagem, modificando os registros materiais históricos.

O patrimônio histórico construído, constituído por edifícios e espaços públicos é um importante bem a ser preservado devido a carga histórica que possui. Neles estão expressas as características de uma sociedade, seus hábitos, costumes, cultura e até mesmo a forma de se socializar, pensar e agir. Além disso, eles são elementos significativos da memória de um povo, uma vez que remetem a sua formação e a criação de sua identidade, como confirma Le Goff (1990), ao defender que a memória é um elemento essencial da identidade, individual ou coletiva.

De acordo com Rodrigues e Machado (2010) a memória é o mecanismo principal para a obtenção da identidade local e social, que se constroem em um indivíduo a partir de visões de mundo, ideologias, experiências e histórias em comum com o grupo social em que vive.

A cidade de Dracena localizada no interior do estado de São Paulo, assim como muitas cidades do oeste paulista, é produto material dos recursos econômicos proporcionada pelo cultivo do café, algodão e amendoim e consequente avanço dos trilhos da Estrada de Ferro no Estado de São Paulo (MUÑOZ, 2014). As características urbanas e arquitetônicas da cidade, remontam a década de 1950, como a abertura de vias principais ao redor da estação rodoviária (futuramente convertida na praça central da cidade), rodeadas de edifícios importantes para a economia e desenvolvimento da cidade, como farmácia, um hotel e a prefeitura, todas com ornamentações de fachadas com características do Art déco.

Segundo Hirao (2010), a construção destas cidades produziram paisagens características, com seus equipamentos públicos e privados, mais os espaços abertos, identificando os locais pelo uso e apropriação socioespacial, proporcionando a construção de um lugar, pela geração de pioneiros, de acordo com as condições econômicas, construtivas e de mão de obra, constituindo-se em um registro desse momento inicial do núcleo urbano, e como tal potencializam seu valor como patrimônio histórico.

Os testemunhos materiais do início de sua ocupação são um registro importante para sua população, pois carregam em suas características, as decisões dos pioneiros da cidade, que são responsáveis pela identidade a ela atribuída. Segundo Schirru (2017, p. 2): “o patrimônio cultural, material e imaterial, configura-se como testemunho da herança de gerações passadas, dando origem e significado ao que se tem no presente, proporcionando aos seus descendentes uma identidade". Por isso a relevância da preservação desses bens, que transmitem às futuras gerações, as referências de um tempo e espaço singular.

Segundo Maia (2003) a educação patrimonial é a responsável por conduzir o homem a esse entendimento, provocando um processo em que ele entende a realidade em que está inserido, 


\title{
Revista Científica ANAP Brasil
}

\author{
ISSN 1984-3240 - Volume 13, número 29, 2020
}

que resulta na consequente valorização de sua cultura. Para Horta, Grunberg e Monteiro (1999, p. 4): "a Educação Patrimonial é um instrumento de "alfabetização cultural" que possibilita ao indivíduo fazer a leitura do mundo que o rodeia, levando-o à compreensão do universo sociocultural e da trajetória histórico-temporal em que está inserido". Assim, ainda segundo os autores, é indispensável no processo de preservação, o conhecimento crítico e a apropriação do patrimônio pelas comunidades, contribuindo para o sentimento de identidade e cidadania.

Segundo Castro (2005) o objetivo da Educação Patrimonial é envolver a comunidade na gestão do patrimônio, uma vez que esta também é responsável pela preservação e conservação dos bens patrimoniais. Esse conhecimento e apropriação das comunidades aos bens patrimoniais são fatores indispensáveis ao processo de preservação, uma vez que, segundo a autora "este processo de valorização e de troca possibilita a geração e produção de novos conhecimentos, num processo contínuo de enriquecimento individual, coletivo e institucional" (CASTRO, 2005, p. 3).

Segundo Abrantes (2014), o uso das tecnologias digitais nas práticas de preservação do patrimônio cultural, é tido como um fator básico para a ampliação do acesso a informação, e logo aos bens culturais, agindo em prol de sua conservação, uma vez que principalmente na era atual vivemos um período marcado por uma transição, com diversas transformações, que resultam num intenso progresso tecnológico, em especial da comunicação. Nesse contexto, o estudo e compartilhamento de informações a respeito de ambientes e edifícios públicos tornase possível, uma vez que essas novas dinâmicas estabelecidas pela relação das cidades com as tecnologias, e destas com os usuários, crescem a cada dia.

Ainda segundo Abrantes (2014, p. 104), a "disseminação é uma forma de preservação dinâmica, pois através das informações propagadas o indivíduo aumenta seu conhecimento a respeito de si mesmo e do espaço em que vive". As informações, segundo Barreto (1999) criam conhecimento modificador e inovador no indivíduo e no seu contexto, fazendo com que este se referencie com o seu mundo de convivência.

As tecnologias digitais surgiram no século XX e revolucionaram a indústria, a economia e a sociedade, uma vez que alteraram as formas de armazenamento e compartilhamento de informações, aumentado consequentemente o acesso a esta. Ela foi responsável pelos debates em torno da relação da humanidade com seu passado, presente e futuro, descentralizando a informação, além de ser a responsável pela criação de muitas outras tecnologias (RIBEIRO, S. d.) As tecnologias digitais estão próximas do homem, se tornaram elementos importantes no seu cotidiano, estão imersas na sociedade. A partir de smartphones, tablets, notebooks, a forma de realização de diversas tarefas foi alterada, pois estes pequenos aparelhos permitem 0 desempenho destas de formas mais simples e prática, alterando a maneira das pessoas trabalharem, se divertirem e interagirem com outras pessoas. As facilidades por elas oferecidas, fizeram com que, principalmente os smartphones, se tornassem uma ferramenta de busca, conexão e difusão de informações, o qual as pessoas necessitam a todo tempo.

$O$ intenso uso das tecnologias digitais e a grande aplicabilidade das ferramentas, por ela oferecidas, no campo da preservação do patrimônio urbano e arquitetônico, tem aberto oportunidades de seu emprego em prol da preservação do patrimônio. Devido a isso, o uso das Tecnologias Digitais oferece uma fonte de ferramentas capazes de auxiliar no reconhecimento, registro e promoção dos bens culturais, ajudando na preservação e valorização do patrimônio 


\title{
Revista Científica ANAP Brasil
}

\author{
ISSN 1984-3240 - Volume 13, número 29, 2020
}

construído. Tendo em vista que o uso de dispositivos móveis, como tablets e smartphones, em horários, lugares e situações diversas, tem se tornado cada vez mais intenso, é possível a utilização de seu alcance como uma forma de contribuir para a educação patrimonial da comunidade.

\section{Objetivos}

O principal objetivo do trabalho, é a elaboração de um modelo de identificação do patrimônio construído, que possa ser desenvolvido a partir do emprego das ferramentas que as tecnologias digitais oferecem, a se dizer: Quick Response code ( $Q R$ code) e website. O uso dessas ferramentas tem como finalidade o rápido e fácil direcionamento dos usuários, através do uso do $Q R$ code, a um acervo virtual e interativo, composto por informações históricas, documentais e registros fotográficos a respeito das obras, que será elaborado a partir da criação de um website com essa finalidade. Além disso, busca-se a integração da população da cidade, através de relatos, comentários e compartilhamento de histórias locais e fotografias, tornando-a em uma plataforma interativa. Este modelo visa contribuir para a educação patrimonial dos citadinos, envolvendo-os com os edifícios que fazem parte da história da cidade através do conhecimento de sua história e processos de transformação, gerando a aproximação das pessoas com estes, potencializando seu processo de valorização e preservação.

\section{Metodologia}

Para realização do objetivo proposto, a metodologia do trabalho compreendeu a sua subdivisão em etapas. Primeiramente foi realizada uma revisão da verificação da identificação e reconhecimento do patrimônio urbano e arquitetônico da cidade de Dracena - SP, material pertencente ao grupo de pesquisa "Projeto, Arquitetura e Cidade" - "Núcleo de Estudos em Patrimônio e Projeto" da UNESP, ao qual o trabalho se vincula.

Em seguida foram escolhidos três edifícios, dentre os que compõem o patrimônio da cidade, para fazerem parte do acervo virtual inicialmente, tendo em vista a possibilidade de sua futura expansão. Dentre os três edifícios escolhidos, realizou-se o teste do modelo de identificação em um deles, para que se pudesse compreender a adesão da população e realizar ajustes de acordo com suas preferências.

Para a obtenção do material necessário a composição do acervo, visitas periódicas foram realizadas ao jornal da cidade e a prefeitura, além da realização de estudos bibliográficos de livros pertencentes ao acervo da cidade, escritos por moradores antigos e historiadores, bem como visitas a páginas da web, e entrevistas com moradores e estudiosos da cidade.

Logo após foi realizado um levantamento bibliográfico de formas de emprego das Tecnologias Digitais como instrumentos voltados à valorização do Patrimônio Urbano e Arquitetônico. Estudou-se a elaboração de acervos virtuais, a partir de referências existentes, além do emprego do QR code como ferramenta de direcionamento rápido.

Pode-se por fim, elaborar e testar um modelo que atuasse na identificação patrimonial de edifícios, e que pudesse ser acessado pelos usuários de forma simples e rápida, além de ser uma plataforma interativa, podendo receber dos próprios moradores, histórias, relatos, fotografias etc. 


\title{
Revista Científica ANAP Brasil
}

\author{
ISSN 1984-3240 - Volume 13, número 29, 2020
}

\section{Resultados}

Os itens 4 e 4.1 deste capítulo foram escritos a partir de uma revisão de dados do Grupo de Pesquisa Projeto, Arquitetura e Cidade - Núcleo de estudos em Patrimônio e Projeto da Unesp, da pesquisadora Muñoz (2014), que para obtenção das informações relacionados a cidade de Dracena - SP, utilizou como fonte de pesquisa o autor Santos (1998). Além desta revisão, foram realizadas pesquisas extras junto a prefeitura municipal, ao jornal da cidade e entrevistas com moradores.

A cidade de Dracena está localizada no interior do Estado de São Paulo, na região conhecida como Nova Alta Paulista. O início de sua ocupação ocorreu em virtude da vinda dos irmãos Fioravante (Virgílio, Demétrio, Humberto e Osvaldo) que em 1936 adquiriram uma gleba de terras pertencente à comarca de Santo Anastácio. A região, coberta de densas florestas, possuía difícil acesso e era conhecida como "Zona da Mata". A iniciativa de estabelecer um núcleo urbano ocorreu em 1945 com a criação da firma Fioravante, Spinardi \& Vendramim Ltda. A fundação da cidade ocorreu no mesmo ano, no dia 8 de dezembro de 1945.

O processo de urbanização de Dracena teve início em agosto de 1945, e no final do mesmo ano, as principais avenidas da cidade, Presidente Roosevelt e Presidente Vargas, já estavam abertas. Os principais motivos que levaram Dracena a um importante e rápido progresso se ligam a sua localização estratégica, as terras férteis e doações de terras a pequenos proprietários, a construção da Estação Ferroviária (que veio a acontecer em 1959, se destacando como fator decisivo para o desenvolvimento econômico e populacional da cidade e da região através do transporte de pessoas e mercadorias), bem como um fundador dinâmico e influente politicamente. Segundo relatos dos moradores da época, o fundador, Irio Spinardi tomava atitudes que promoveram o desenvolvimento acelerado da cidade, como a obrigatoriedade da construção de edificações em alvenaria ao redor da antiga rodoviária (atual Praça Arthur Pagnozzi) para que o visitante que chegasse à Dracena se deparasse com uma cidade em desenvolvimento, e não com um povoado, conforme dito em entrevista realizada por Muñoz com o historiador dracenense, Rogério Edson dos Santos.

\subsection{Patrimônio urbano e arquitetônico}

No final da década de 1940 Dracena já apresentava um acentuado crescimento, o que tornou o centro da cidade um canteiro de obras. Várias novas edificações começaram a surgir, principalmente no entorno do Terminal Rodoviário (atual Praça Arthur Pagnozzi). Nos arredores da antiga rodoviária foram implantados importantes equipamentos públicos, como a Prefeitura Municipal e o Fórum e inúmeros edifícios comerciais e de serviços. A Figura 1 mostra a localização dos edifícios no centro de Dracena - SP. 


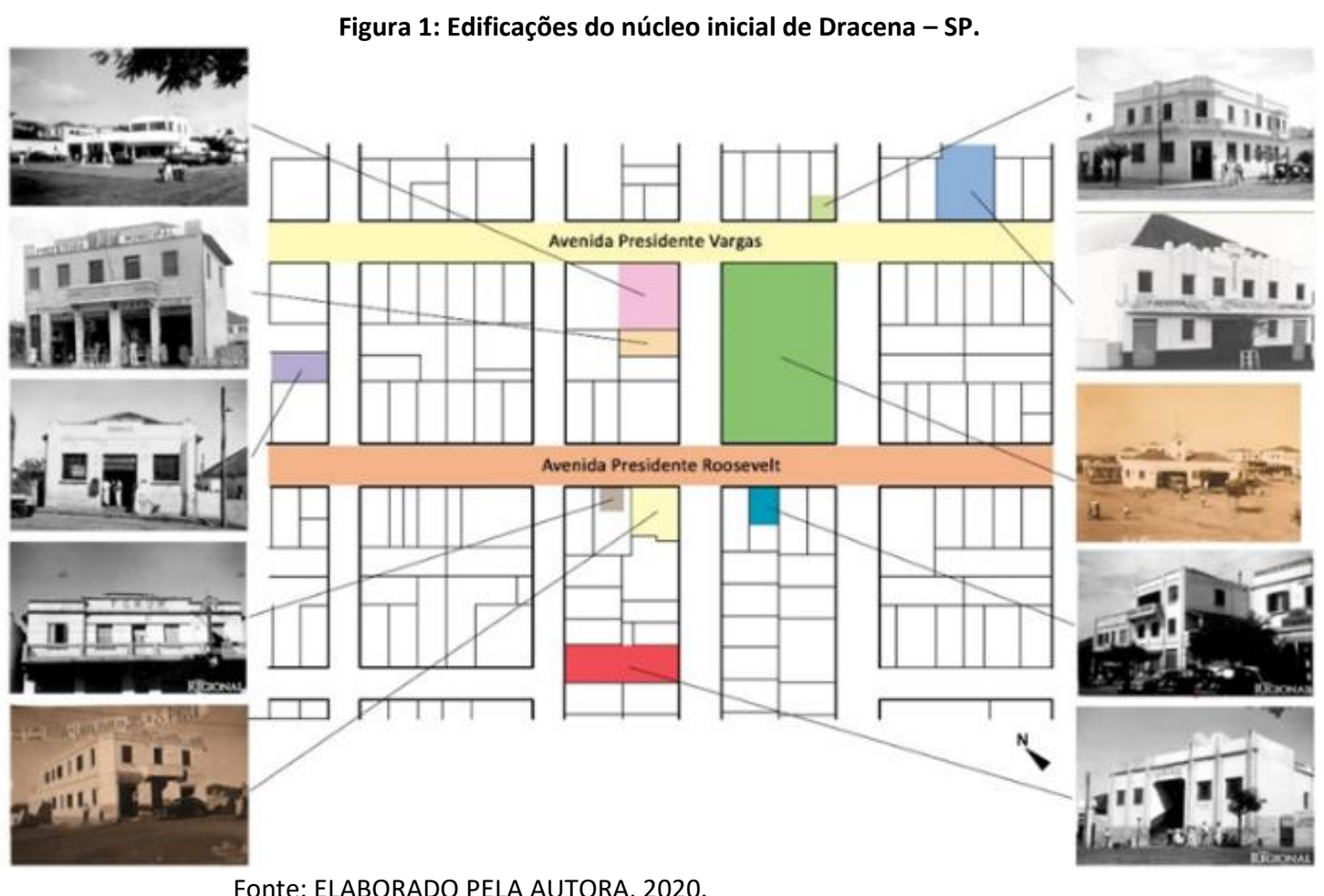

Em 1952 houve a realização de diversas obras de embelezamento da cidade. Nesta mesma década o terminal rodoviário foi transferido para um lote a 400 metros de distância do local em que se encontrava, e que foi transformado na praça central da cidade recebendo o nome de Praça da Bandeira, a qual em 1957 ganha uma fonte e um jardim. Nesse mesmo período, iniciase, também a construção da catedral Igreja Matriz.

Ainda hoje a cidade de Dracena apresenta registros materiais do início de sua ocupação. Ela é produto material dos recursos econômicos proporcionada pelo cultivo do café, algodão e amendoim e consequente avanço dos trilhos da Estrada de Ferro no Estado de São Paulo. Os núcleos urbanos iniciais e as paisagens características dessa época, são constituídas por construções feitas de acordo com as possibilidades econômicas, de material construtivo e mão de obra, criando fortes identidades locais.

A paisagem inicial da cidade sofreu alterações. Com o passar do tempo e devido as necessárias intervenções para as finalidades de uso, alguns edifícios e espaços abertos foram reformados, outros descaracterizados, muitos demolidos, e alguns abandonados. Estes registros históricos, contudo, são testemunhos significativos da arquitetura e urbanismo produzidos pela geração que deu início ao processo urbano da cidade. Os equipamentos do núcleo inicial caracterizam as transformações pelas quais a cidade passou. As edificações centrais apresentam características do Art-Déco e são hoje utilizadas para fins distintos dos iniciais.

Para a realização deste trabalho foram escolhidas três edificações do patrimônio urbano e arquitetônico da cidade, para inicialmente comporem o acervo digital, podendo este ser expandido posteriormente com outras edificações.

\section{- Estação Ferroviária}




\title{
Revista Científica ANAP Brasil
}

\author{
ISSN 1984-3240 - Volume 13, número 29, 2020
}

A Estação Ferroviária de Dracena foi implantada no final da década de 1950, e o primeiro trem chegou na cidade por volta do dia 30 de dezembro de 1959. A linha férrea fazia parte do Tronco Oeste da Companhia Paulista de Estradas de Ferro, e promovia a ligação entre o Rio Paraná e a cidade de Itapira, sendo responsável pelo transporte de cargas e passageiros. A presença da linha férrea representava entre outros fatores, o desenvolvimento da região. A ferrovia era vista como símbolo de modernidade e progresso uma vez que permitia a ligação da cidade com cidade maiores, num tráfego mais rápido e maior de cargas e pessoas.

A edificação foi utilizada como Estação até o ano de 1998, quando o trem foi desativado em virtude da implantação das Rodovias, a partir de então, a estação ferroviária foi abandonada. Em 2003 houve uma tentativa do poder público em dar finalidade ao prédio da Estação. Para isso o prédio passou por reformas com o propósito de abrigar um centro cultural, tal uso perdurou até agosto de 2013. O prédio permaneceu fechado por alguns anos e foi cedido, tempos depois, pela prefeitura para exposição de arte de um artista da cidade. Atualmente o local encontra-se aos cuidados deste artista, porém, segundo o mesmo, sem qualquer apoio do município. A Figura 2 mostra a Estação Ferroviária atualmente.

Figura 2: Estação Ferroviária no ano de 2019.

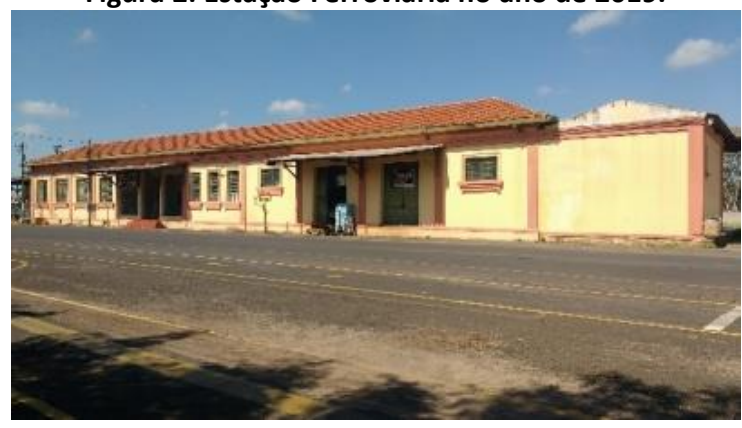

Fonte: ACERVO DA AUTORA, 2019.

\section{- Mercado Municipal}

Os registros do Mercado Municipal são em sua maioria provenientes de relatos orais a partir de conversas com moradores da cidade e fotografias fornecidas por órgãos municipais, entidades particulares e antigos moradores.

A primeira edificação a ser construída no local onde hoje se encontra o Mercado Municipal, foi um barracão de madeira utilizado para bailes, festas e até mesmo um cinema. Este barracão deu lugar ao prédio em alvenaria que comporta o Mercado Municipal atualmente.

Não foram encontrados documentos que comprovem a data de sua construção, porém segundo relatos e fotografias o prédio de alvenaria já era existente no final na década de 1950. Moradores antigos da cidade relatam que nos primeiros anos de sua existência, o "Mercadão", como ficou conhecido devido ao seu tamanho, era bastante movimentado, devido ao fato de ser o único local para compra e venda de frutas, verduras e carnes. Internamente ele é subdividido em salas, que inicialmente eram totalmente ocupadas, hoje, porém com a venda destes produtos em grandes redes de supermercados, o Mercado Municipal passou a abrigar lojistas e prestadores de serviços variados, não tendo suas salas totalmente ocupadas. 


\title{
Revista Científica ANAP Brasil
}

\author{
ISSN 1984-3240 - Volume 13, número 29, 2020
}

O edifício ficou desgastado com o passar dos anos, possuindo suas esquadrias e pintura deterioradas. No ano de 2015 o local passou por uma reforma, o que, segundo relatos de usuários, atraiu mais frequentadores, porém, ainda hoje o movimento é menor do que o das décadas anteriores. A Figura 3 mostra o Mercado Municipal nos dias de hoje.

Figura 3: Mercado Municipal no ano de 2019.

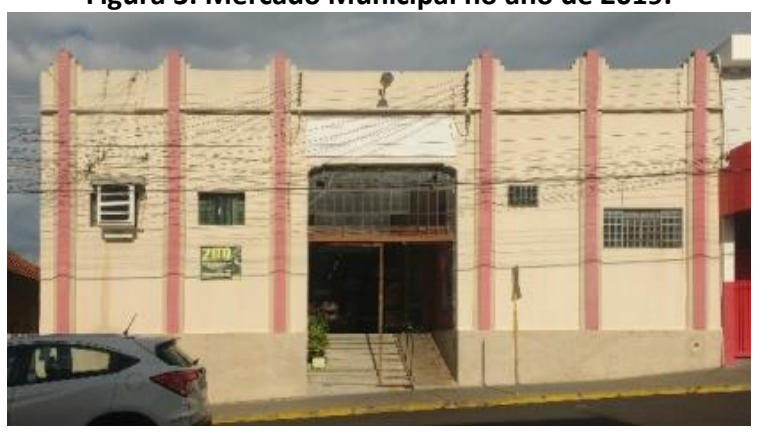

Fonte: ACERVO DA AUTORA, 2019.

- Praça Arthur Pagnozzi

A Praça Arthur Pagnozzi está localizada bem ao centro da cidade de Dracena. Inicialmente no local foi construída a primeira rodoviária da cidade entre os anos de 1948 e 1949. Em seu entorno se fixaram os primeiros edifícios que constituiriam o centro urbano da cidade, como a prefeitura, um hotel e farmácia. No ano de 1957, a rodoviária foi transferida para um outro local a 400 metros, dando espaço para a implantação da chamada Praça da Bandeira, a atual Praça Arthur Pagnozzi.

Inicialmente a Praça recebeu uma fonte localizada próxima a esquina entre as ruas Presidente Roosevelt com a Expedicionários. A fonte ainda faz parte das características do local, hoje, porém, ela foi modificada e encontra-se na parte central da Praça. A partir de registros fotográficos, observa-se características que foram incorporadas e posteriormente removidas no decorrer dos anos, como uma torre de relógio, aparelhos telefónicos, escadas que davam acesso a Praça e muretas em sua volta, um coreto, um aquário, entre outras características que marcaram o local num determinado período de tempo. Devido as modificações, hoje a Praça encontra-se um pouco diferente (Figura 4), entre outros atributos, ela possui, a fonte central, citada anteriormente, uma estrutura coberta para palco e um monumento em homenagem aos cem anos da imigração japonesa, cultura muito presente na cidade.

Desde sua inauguração, a Praça foi utilizada como local de encontro, passeio e lazer, recebendo sempre muitos visitantes. Ela ainda é palco de diversos eventos como as comemorações do natal, feiras itinerantes, comércio alimentício, shows e eventualmente recebe um parque infantil. A Praça Arthur Pagnozzi está muito presente na vivência dos citadinos, em suas histórias e memórias, e devido a isso é um espaço urbano muito importante pra cidade. 


\title{
Revista Científica ANAP Brasil
}

\author{
ISSN 1984-3240 - Volume 13, número 29, 2020
}

Figura 4: Praça Arthur Pagnozzi no ano de 2019.

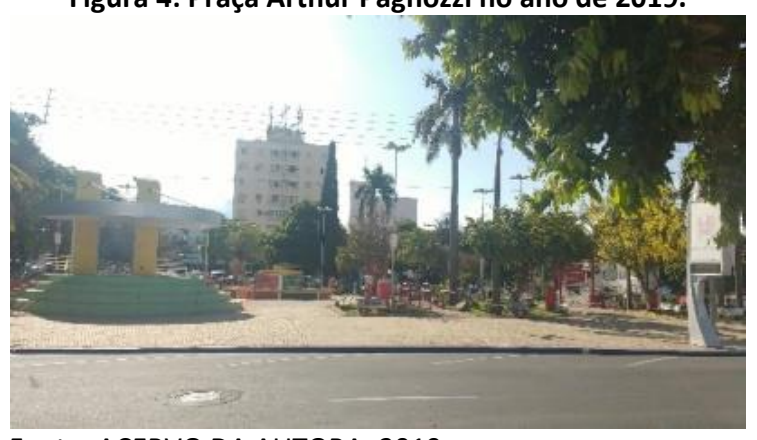

Fonte: ACERVO DA AUTORA, 2019.

\subsection{Elaboração e teste do modelo de identificação}

O objetivo proposto se trata da criação de um acervo virtual interativo, composto por histórias, memórias, vivências, fotografias, entre outros, que possa ser acessado pelo aparelho celular a partir do próprio local onde se encontra o patrimônio. Assim estando no local, o usuário poderia conhecer um pouco melhor da sua história e compreender o processo de transformação que o edifício passou.

A criação do acervo digital contendo fotos, histórias, relatos, entre outros, teve como base os acervos digitais existentes, bem como páginas da web direcionadas ao compartilhamento de registros históricos. O modelo foi testado em uma das três edificações escolhidas, para comporem o Acervo, o Mercado Municipal, a fim de se compreender a adesão da população, e realizar eventuais ajustes.

Para o levantamento do material necessário a composição do acervo, foram realizadas visitas a Prefeitura Municipal de Dracena, ao jornal da cidade e aos próprios patrimônios escolhidos, com entrevistas informais aos usuários.

O primeiro passo para a criação do acervo foi a edição de um site que funcionasse como uma plataforma de compartilhamento de conteúdo, os sites são várias páginas web juntas que tratam dos mais diversos assuntos, e podem ser editadas a todo momento. Essa etapa foi realizada utilizando-se os recursos gratuitos oferecidos pela Wix.com, Inc. O Wix.com é uma empresa que fornece aos usuários a possibilidade de criação de sites, a plataforma é de fácil entendimento não necessitando de conhecimentos técnicos para sua utilização. As próprias ferramentas te direcionam para a criação de templates que podem ser editados a todo o tempo e das mais diversas formas.

Após a composição do acervo virtual, com as informações obtidas, realizou-se a publicação do site (Figura 5). O Wix.com gera automaticamente um link de acesso e este foi de vital importância para a criação do $Q R$ code. 


\title{
Revista Científica ANAP Brasil
}

\author{
ISSN 1984-3240 - Volume 13, número 29, 2020
}

Figura 5: Página do Mercado Municipal no Acervo Virtual.

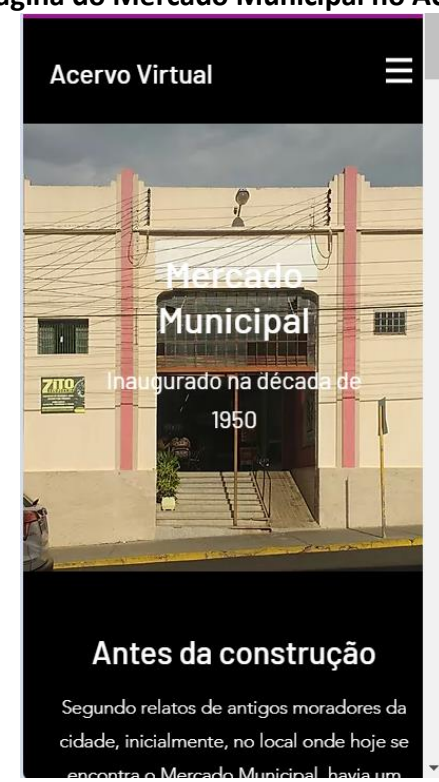

Fonte: ELABORADO PELA AUTORA, 2020.

O QR code é uma espécie de código de barras, composto pela combinação de símbolos em 2D capazes de armazenar informações como textos, arquivos, páginas da internet, mensagens, números de telefones entre outros. O conteúdo armazenado nesses $Q R$ codes, pode ser acessado por meio de aparelhos celulares, ao apontar a câmera do aparelho, ele realiza a leitura e direciona o usuário ao conteúdo previamente preparado.

A criação de $Q R$ codes pode ser facilmente realizada pela internet, através de sites específicos que oferecem este serviço. Há desde planos grátis e, portanto, mais simples que permitem a criação do código e seu livre funcionamento, a planos mais sofisticados, e, portanto, pagos, que possuem mais funcionalidades.

Para a realização deste trabalho, foi escolhido a utilização dos recursos gratuitos oferecidos pelo $Q R$ code generator, uma empresa que oferece uma ferramenta rápida e fácil para criação de $Q R$ codes. O processo para sua criação é simples, ao acessar o site o usuário escolhe o tipo de conteúdo que deseja compartilhar através do código que será gerado. Foi escolhido a opção de URL, utilizado para o direcionamento a sites, neste local foi inserido o link gerado anteriormente. A partir do emprego das ferramentas apresentadas um modelo inicial foi elaborado, este serviu para compreensão da adesão da população ao Acervo Digital, como mostra a Figura 6. O modelo inicial foi testado durante sete dias em uma das edificações escolhidas - O Mercado Municipal. Ele foi fixado com a permissão do responsável pelo estabelecimento que se encontra logo a entrada, para que sua visualização e acesso fossem facilitadas, como pode ser visto na Figura 7. 


\section{Revista Científica ANAP Brasil}

\section{ISSN 1984-3240 - Volume 13, número 29, 2020}

Figura 6: Modelo teste.

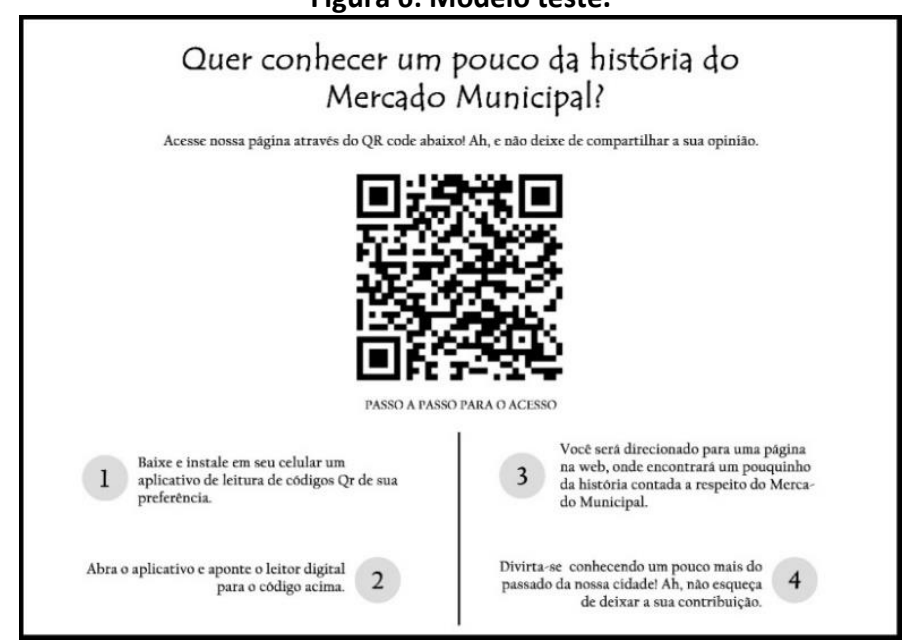

Fonte: ELABORADO PELA AUTORA, 2020.

Figura 7: Aplicação do modelo teste no Mercado Municipal.

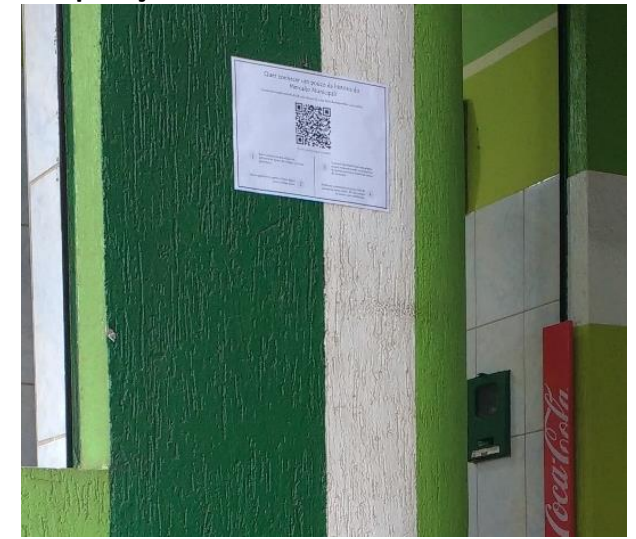

Fonte: ACERVO DA AUTORA, 2020.

Com apenas quatro dias de teste, o Acervo Virtual recebeu cinco visitantes, sendo que dois deles deixaram comentários, como mostra o Quadro 1. O número de visitantes e os comentários deixados por eles ficam visíveis na própria plataforma em que se criou o website.

Quadro 1: Comentário de usuários do acervo no período de teste.

\begin{tabular}{|c|c|}
\hline Usuário & Comentário \\
\hline Usuário 1: Valter & "Deixe espaços para enviarmos fotos!!!" \\
\hline Usuário 2: Matheus & $\begin{array}{c}\text { "O mercadão de Dracena nos traz varias recordações. } \\
\text { Sendo que maior é quando meu pai me levava para } \\
\text { comer pastel todo sabado. }\end{array}$ \\
Até hoje o local é referência na cidade no sabor dos \\
seus pasteis."
\end{tabular}

A partir da contribuição dos usuários com relatos, suas opiniões a respeito da plataforma, e através de estudos mais aprofundados, melhorias foram implantadas no Acervo Digital. Com o frequente uso da população, este tende a ter mais contribuições, passando a adquirir as características e a identidade da comunidade. 


\title{
Revista Científica ANAP Brasil
}

\author{
ISSN 1984-3240 - Volume 13, número 29, 2020
}

\section{Conclusão}

A aplicação do modelo obteve êxito, pois em menos de uma semana foram alcançadas no mínimo cinco pessoas, como registrado pela plataforma do website. Porém, devido ao fato de a plataforma contabilizar o acesso a partir do número de aparelhos que se conectaram, não podendo contabilizar a quantidade de pessoas que obtiveram acesso a informação a partir do mesmo aparelho, sabe-se que este número pode ter sido maior.

Além dos acessos, o Acervo contou ainda com a participação da população, através de respostas e contribuições para sua melhoria. Estas foram implantadas, e outras características do Acervo também puderam ser modeladas de acordo com as preferências da comunidade.

O acesso e a participação da população revelam-se como um avanço nas possibilidades de utilização deste instrumento nas práticas de educação patrimonial, que capacita o indivíduo à leitura e a compreensão da sociedade e cultura em que se está inserido, resultando em conhecimento e apropriação das comunidades aos bens patrimoniais. Este por sua vez, resultou numa contribuição ao processo de potencialização da valorização e preservação do patrimônio urbano e arquitetônico da cidade de Dracena - SP.

Cabe também destacar a possibilidade de utilização deste modelo em diversos lugares, e de formas variadas, servindo como instrumento para valorizar processos de preservação a ser utilizado entre outros, por órgãos municipais que visam a salvaguarda do patrimônio municipal.

\section{AGRADECIMENTO}

A Pró-reitora de Pesquisa da UNESP pelo financiamento da iniciação científica que deu base a este artigo e ao Professor Hélio Hirao pela orientação.

\section{REFERÊNCIAS BIBLIOGRÁFICAS}

ABRANTES, A. R. Tecnologias Digitais como Instrumentos de Preservação do Patrimônio Urbano Edificado. 2014. Dissertação (Mestrado em Preservação do Patrimônio Cultural) - Instituto do Patrimônio Histórico e Artístico Nacional, Rio de Janeiro, 2014.

BARRETO, A. A. A oferta e a demanda da informação: condições técnicas, econômicas e políticas. Ciência da Informação, Brasília, v.28, n.2, 1999. Disponível em: <http://revista.ibict.br/ciinf/article/view/847/880> Acesso em: 13 abr. 2020

CASTRO, C. A importância da Educação Patrimonial para o desenvolvimento do Turismo Cultural. In: III Seminário de Pesquisa em Turismo do Mercosul, 2005, Caxias do Sul. III Seminário de Pesquisa em Turismo do Mercosul, 2005. [Anais]. Disponível em: <https://www.ucs.br/site/midia/arquivos/gt5-a-importancia.pdf> Acesso em: 10 jan. 2020.

HIRAO, H. Arquitetura moderna paulista, imaginário social, uso e apropriação do espaço. Presidente Prudente, 2008. Tese (Doutorado em Geografia - Área de Concentração: Produção do Espaço Urbano) FCT/ UNESP.

HORTA, M L. P. GRUNBERG, E. MONTEIRO, A. Q. Guia básico de educação patrimonial. Brasília: Iphan - Museu Imperial, 1999.

LE GOFF, J. História e memória. Tradução Bernardo Leitão [et al.] - Campinas, SP Editora da UNICAMP, 1990. 


\title{
Revista Científica ANAP Brasil
}

\author{
ISSN 1984-3240 - Volume 13, número 29, 2020
}

MAIA, F. A. Direito à Memória: O Patrimônio Histórico, Artístico e Cultural e o Poder Econômico. Movendo Ideias, Belém, v. 8, n. 13, p. 39-42, jun 2003.

MUÑOZ, L. S. Paisagens do centro histórico de Dracena: função e significado na cidade atual. Relatório de Iniciação Científica, Presidente Prudente - SP, 2014.

RIBEIRO, A. E. Tecnologia Digital. [2015?] Disponível em:

<http://www.ceale.fae.ufmg.br/app/webroot/glossarioceale/verbetes/tecnologia-digital>. Acesso em: 15 jan. 2020.

RODRIGUES, G.G.; MACHADO, N.T.G. A importância da memória para uma cidade. Revista Destaques Acadêmicos Cchj/UNIVATES, Lajeado -RS, ano 2, n. 2, p. 23-26, 2010. Disponível em:

<http://www.univates.br/revistas/index.php/destaques/article/view/61/59> Acesso em: 7 jan. 2020.

SANTOS, R. E. dos. Viajando no História. Dracena, 1998.

SCHIRRU, A. C. C. A Importância do Patrimônio Cultural para a cidade: Identidade Social e Planos Urbanos. In: IX MESTRES E CONSELHEIROS - AGENTES MULTIPLICADORES DO PATRIMÔNIO, 2017, Belo Horizonte. [Anais].

Disponivel em: <https://www.even3.com.br/anais/mestreseconselheiros2017/50792-a-importancia-do-patrimoniocultural-para-a-cidade--identidade-social-e-planos-urbanos/>. Acesso em: 7 jan. 2020. 